\title{
Role of laser application in endodontic treatment: a review of literature
}

\author{
Abdulkader Abdulelah Abulhamayel ${ }^{1 *}$, Khalid Abdulbaqi Alsulami ${ }^{2}$, Ali Nasser Alshehri ${ }^{3}$, \\ Abdullah Hussain Alasmari ${ }^{4}$, Faisal Ramadan Alzahrani ${ }^{2}$, Majid Abdulkader Altayeb ${ }^{5}$, \\ Abdullah Ibrahim Almane ${ }^{6}$, Alhanouf Khaled Alshehri ${ }^{7}$, Faisal Mohammed Alotaiby ${ }^{8}$, \\ Abdullah Mufarrih Algahtani ${ }^{9}$, Mohammed Saeed Algthaiae ${ }^{9}$
}

\author{
${ }^{1}$ Department of Endodontics, Khulais General Hospital, Khulais, Saudi Arabia \\ ${ }^{2}$ College of Dentistry, King Abdulaziz University, Jeddah, Saudi Arabia \\ ${ }^{3}$ General Dentist, Ministry of Health, Alnamas, Saudi Arabia \\ ${ }^{4}$ General Dentist, Ministry of Health, Muhayil Asir, Saudi Arabia \\ ${ }^{5}$ General Dentist, Ministry of Health, Medina, Saudi Arabia \\ ${ }^{6}$ General Dentist, Dent Clinics, Riyadh, Saudi Arabia \\ ${ }^{7}$ College of Dentistry, Riyadh Elm University, Riyadh, Saudi Arabia \\ ${ }^{8}$ General Dentist, East Jeddah Hospital, Jeddah, Saudi Arabia \\ ${ }^{9}$ General Dentist, Ministry of Health, Riyadh, Saudi Arabia
}

Received: 11 May 2021

Accepted: 28 May 2021

\section{*Correspondence:}

Dr. Abdulkader Abdulelah Abulhamayel,

E-mail: abdulkader77@gmail.com

Copyright: (C) the author(s), publisher and licensee Medip Academy. This is an open-access article distributed under the terms of the Creative Commons Attribution Non-Commercial License, which permits unrestricted non-commercial use, distribution, and reproduction in any medium, provided the original work is properly cited.

\begin{abstract}
Many applications have been previously reported that laser is used in the field of endodontics. It is used in pulp diagnosis, shaping and disinfection of the root canal, endodontic surgeries, modifying the dentin structures, pulpotomy and pulp capping. Our present study aims to review some applications of laser used in the field of endodontics. According to the evidence from current studies in the literature, vital pulp therapeutic approaches for pulpotomy can significantly lead to efficacious and bloodless outcomes by using laser for the following processes: Coagulation, vaporization, and sealing of the blood vessels with potentially sterile minute wounds with no complications. Many advantages have been previously reported for using laser within endodontic surgical procedures, such as coagulation, sterilization, selective absorption, precision, lower rates of complications as inflammation and edema, getting clean, well-sealed surgical wounds, enhanced disinfection characteristics, reduced painful sensations, decreased required sutures due to better hemostasis, and reduced bleeding. On the other hand, applying some laser modalities might not be adequately efficacious according to previous studies in the literature. We recommend that further human prospective to conduct investigations for further validation of the current evidence.
\end{abstract}

Keywords: Endodontics, Laser, Disinfection, Dentistry, Pulpotomy

\section{INTRODUCTION}

Endodontic procedures are mainly directed to reduce the rates of infections and to remove the potentially present pulp tissue from the root canal to prevent the growth of the microorganisms. Moreover, such procedures are also meant to reduce the potentiality and severity of inflammation by eliminating any accumulation of forcing debris behind the apical foramen. ${ }^{1-3}$ Many complications and adverse events have been related to endodontic therapeutic approaches. Among these complications such as anatomical complexity, morphologies of the lateral canals and apical ramifications made it difficult to penetrate through these structures by commonly reported irrigation modalities. ${ }^{4}$ 
According to the increasing challenges within the endodontic field, approaches have been made to innovate better techniques and to enhance the underlying technological applications that aim to improve the disinfection strategies and to clean characteristics of these hard-to-reach sites. Laser techniques were successfully introduced in the field of dentistry in 1965 by Leon Goldman who applied the modality in vivo. However, no success could be obtained because of the increased thermal energy. ${ }^{5-8}$ Consequently, Weichman and Johnson introduced the modality in the field of endodontics in 1971 by using $\mathrm{CO}_{2}$ laser modalities. However, no successful outcomes were also reported by the authors in vitro study. ${ }^{9}$ Other laser modalities as $\mathrm{Nd}$ : YAG, and Er: YAG wase also introduced in the following years by other investigations. Finally, Er: YAG was approved by the United States federation of drug and food in 1997, which was the spark that allowed laser modalities and endodontics to be used in the field of dentistry. ${ }^{3}$

Using laser techniques in endodontics mainly aims to improve cleaning and disinfection abilities more than the previously reported modalities to enhance the outcomes and to reach the areas that were previously reported to be difficult to clean through using light energy. Moreover, removal of debris, eliminating the microorganisms, and prevention of adverse events have been previously reported in applying laser in endodontics. Many applications have been previously reported for laser is used in the endodontic field, such as pulp diagnosis, shaping and disinfection of the root canal, endodontic surgeries, modifying the dentin structures, pulpotomy and pulp capping. ${ }^{10}$ Our present study aims to review some applications of laser that are used in the field of endodontics related to evidence from current studies in the literature.

\section{METHODS}

A systematic search was conducted to identify relevant studies in the following databases: PubMed, Medline, Web of Science, Embase, Google Scholar, and Scopus. The following search terms were used ("endodontics") and ("laser") and ("treatment"). The reference lists were manually searched to identify additional relevant studies meeting inclusion criteria. We included any study that reports iatrogenic tooth discoloration by obturating material. No restrictions were applied.

\section{DISCUSSION}

\section{Pulpotomy and pulp capping}

Vital pulp therapeutic approaches for pulpotomy can significantly lead to outcomes that are efficacious and bloodless using the laser in any of the following processes, including coagulation, vaporization, and sealing of the blood vessels with potentially sterile minute wounds with no complications. A previous animal study on monkeys and dogs that was previously done by Melcer et al reported that hemostasis was successfully obtained in the study sample using $\mathrm{CO}_{2}$ laser for pulpotomy procedures. ${ }^{11}$ Another previous comparative investigation also compared the efficacy of $\mathrm{CO}_{2}$ laser and calcium hydroxide for performing successful pulp capping procedures. Furthermore, the authors reported that the $\mathrm{CO}_{2}$ laser approach was more significantly successful than the calcium hydroxide because the $\mathrm{CO}_{2}$ laser obtains successful pulp capping procedures with success rates of $89 \%$ and $68 \%$ respectively over a 12-month follow-up period. ${ }^{12}$ Nair et al has also conducted a follow-up study to examine the effect of using $\mathrm{CO}_{2}$ laser on performing successful pulpotomy procedures in five teeth over seven days and three months. ${ }^{13}$ The authors reported that they did not notice any potential complications related to the teeth at the pulp-dentin complex over the seven days following the application of $\mathrm{CO}_{2}$ laser. On the other hand, at the three months of follow-up, they reported that the teeth were subtle, but distinct dentin at the same position the laser was performed was observed in two of the included teeth. Besides, they also observed that postoperative results following $\mathrm{CO}_{2}$ laser applications also showed that one tooth developed an inflammatory status, and the authors were able to detect some chronic inflammatory cells, however, they reported that such events were not related to performing the $\mathrm{CO}_{2}$ laser procedures, but these events were related to the development of antigen-antibody complexes and potential immune responses or they were due to a potential leakage at the same location. Another 12-month comparative investigation also compares the efficacy and safety of using formocresol one and $\mathrm{Nd}$ : YAG laser according to radiographical, clinical, and histopathological outcomes. The authors reported that after the end of the follow-up period, the formocresol groups showed higher success rates than the laser group with an estimated $90.47 \%$ for the clinical and radiographical assessments, compared to $85.71 \%$ and $71.42 \%$ for the laser group, respectively. ${ }^{14}$ It is worth mentioning that previous investigations recommended that clinicians should approach capping when patients are young and having minimal exposure while pulpotomy should be performed when the roots are not completely formed and whenever caries exposure is present. $^{15,16}$

As calcium hydroxide, which has been the traditionally applied material for capping was associated with the secondary development of a necrotic layer, investigations reported that mineral trioxide aggregate can significantly replace this material with better-obtained outcomes although it might need a longer operative period. ${ }^{11,17-19-21}$ Previous investigations reported that using a 9,600 nm $\mathrm{CO}_{2}$ laser can significantly induce melting ablation and solidification of the targeted tissues with no significantly apparent adverse events. ${ }^{22,23}$ Besides, for the Nd: YAG laser, White et al reported that to obtain safer outcomes with fewer adverse events, the repetition and energy values of the modality should not exceed $10-\mathrm{Hz}$ and $1 \mathrm{~W}$, in addition to having an exposure period that is less than 10 seconds, however, it should be noted that the findings 
were obtained from vivo experiments and that clinicians should consider lower safety limits when operating in humans. ${ }^{24}$ It is worth mentioning that using $\mathrm{CO}_{2}$ laser can be time-consuming and can be frequently repeated leading to chance the exposure and cause frequent complications. ${ }^{23}$ Moreover, the previous study by White et al also reported that pulsed ND: YAG laser modalities are probably associated with more adverse events with lower success rates. $^{24}$ Therefore, The use should be limited to fixing the pulp inflammation, sedation, hemostasis, and induction of the other adjacent cells.

\section{Irrigation and disinfection of the root canal}

Many studies in the literature have been previously published reporting the potential use of laser modalities including the yellow tube (by Er: YAG and $\mathrm{CO}_{2}$ ), and the thin fibers (by argon, chromium, iodide, ND: YAG, and erbium) in delivering the omitted power from these laser modalities into the targeted root canal, which can be significantly used as disinfecting agents. Studies have shown that the emitted energy from the laser modalities can eliminate the potential present microorganisms, and the efficacy of such modalities is greatly dependent on the amount and frequency of the emitted energy from the used modalities. Removal of debris and disinfection following the process of biochemical instrumentation has been previously reported among several studies in the literature with the aforementioned laser modalities. ${ }^{25-37} \mathrm{~A}$ previous investigation reported that eliminating $E$. faecalis was successfully obtained using the diode lasers 980 nm. ${ }^{38}$ Another investigation reported that ND: YAG laser modality could disinfect the dental surfaces that were priorly infected with different Candida species. ${ }^{39}$ Recently, after antimicrobial photodynamic therapy (APDT) was introduced and successfully validated, it has been recommended to be potentially used within the regular protocols for the routine disinfection procedures, in addition to applying other chemical antimicrobials and mechanical cleaning protocols. ${ }^{40}$ A previous comparative study by Garcez et al previously compared the use of APDT versus the regular antimicrobial modalities and the combined administration of both modalities in their efficacy to reduce the infections. ${ }^{41}$ They reported that the combined application of both modalities was $98 \%$ efficacious while using the regular root canal therapy and the APDT alone were efficacious by $90 \%$ and $95 \%$, respectively. The authors also previously reported that as the regular mechanical disinfection root canal procedures were able to reduce and eliminate the disinfections, applying APDT was furtherly able to eliminate the antimicrobial-resistant organisms. ${ }^{42}$ Another investigation by Garcez et al also reported that to eliminate E. faecalis, APDT with optical fibers should be used rather than any other modalities with proven high success rates. ${ }^{43}$

Photo-activated disinfection has also been reported among studies in the literature as an efficacious modality that is majorly based on obtaining a specific wavelength and using a photosensitizing dye. Studies have proven that the technique can kill bacteria by inducing membrane rupture through activation of reactive oxygen species and releasing more free radicals that are toxic to the bacteria. ${ }^{44,45}$ Moreover, a previous investigation also reported that $\mathrm{PAD}$ and sonic activated irrigation were both highly efficacious in obtaining better disinfection outcomes as compared to the other modalities. ${ }^{45}$ However, it is worth mentioning that the direct application of laser to the root canals might lead to the development of some adverse events, however, using PAD might probably lower the risk of developing such complications. Photodynamic therapy by low-energy light-emitting diode and toluidine blue $\mathrm{O}$ was also previously reported in the literature to be applied as an adjuvant disinfecting modality. ${ }^{46}$

\section{Periapical curettage, apicoectomy, and endodontic- related cavity preparation}

According to an investigation in the literature, the application of laser in endodontic procedures and surgeries is similar to other oral surgeries. For instance, to better-enhanced access to the periradicular region, laser techniques that are used for soft tissues as Diode, $\mathrm{CO}_{2}$, and ND: YAG to significantly get enhanced clean and sound incisions with no secondary complications that can affect the procedure. Moreover, previous studies have also demonstrated that using laser techniques in such operations can significantly lower the risk of developing complications such as blood-borne contaminations from the surrounding surgical practices and such as compared to the related aerosol-producing materials used for periapical procedures. ${ }^{47}$

Many advantages have been previously reported for using laser within endodontic surgical procedures. For instance, coagulation, sterilization, selective absorption, precision, lower rates of complications as inflammation and edema, getting clean and well-sealed surgical wounds, enhanced disinfection characteristics, reduced painful sensations, decreased required sutures due to better hemostasis, and reduced bleeding. Evidence also shows that $\mathrm{CO}_{2}$ laser and pulsed Nd: YAG modalities can also be effectively used in the management of sinus tract periapical disorders. ${ }^{47,48}$ On the other hand, a previous animal study that was conducted on dogs investigated the efficacy of $\mathrm{CO}_{2}$ laser techniques in enhancing the success rates of apical procedures. The authors reported that the technique was potentially able to reduce the permeability of the related dentin, but the overall success rates of the procedures were not significantly enhanced after applying $\mathrm{CO}_{2}$ laser techniques. ${ }^{49}$

The same findings were also reported by a previous comparative prospective investigation that compared 320 cases with two different apical preparations. The authors reported that no significant enhancement in the healing processes of the included patients was noticed when using $\mathrm{CO}_{2}$ laser modalities. ${ }^{50}$ On the other hand, previous in vitro investigations were conducted to assess the efficacy 
of the Nd: YAG modality and found that reduced dye and bacterial penetrations were obtainable by the modality that was mainly used for root resection. This can be explained by the potentially significant changes that were made to the dentin structures by the applied laser modality, leading to reduced permeability in the operated specimens. Moreover, previous investigations that applying the laser modality was furtherly useful in reducing the permeability but not preventing it, and therefore, the rates of complications and enhanced healing might additionally favor the application of the modality.

Previous studies have demonstrated the potential benefits from using low laser levels, as previous investigations reported that significant discomforting sensations were reported by many patients following periodontal surgical practices with Er: YAG modalities. It is worth noting that applying Er: YAG can significantly increase the chances of getting clean surfaces and less frequent complications while investigations also reported that significant thermal damage might be associated with using the Ho: YAG modality.

\section{CONCLUSION}

In the present literature review, we have discussed the roles that laser modalities play in endodontic treatment practices. Many advantages have been previously reported for using laser within endodontic surgical procedures. For instance, coagulation, sterilization, selective absorption, precision, lower rates of complications as inflammation and edema, getting clean and well-sealed surgical wounds, enhanced disinfection characteristics, reduced painful sensations, decreased required sutures due to better hemostasis, and reduced bleeding. On the other hand, applying some laser modalities might not be adequately efficacious according to previous studies in the literature. We recommend that further human prospective to conduct investigations for further validation of the current evidence.

\section{Funding: No funding sources Conflict of interest: None declared \\ Ethical approval: Not required}

\section{REFERENCES}

1. Mohammed H, Hamad A, Mengari L. Lasers in endodontics. Indo Global J Pharmaceutical Sci. 2019;06:1415-21.

2. Yamamoto H, Sato K. Prevention of dental caries by acousto-optically Q-switched Nd: YAG laser irradiation. J dental res. 1980;59(2):137.

3. Adrian JC, Bernier JL, Sprague WG. Laser and the dental pulp. J Am Dental Asso. 1971;83(1):113-7.

4. Gulabivala K, Patel B, Evans G, Ng Y-L. Effects of mechanical and chemical procedures on root canal surfaces. Endodontic Topics. 2005;10(1):103-22.
5. Goldman L, Hornby P, Meyer R, Goldman B. Impact of the laser on dental caries. Nature. 1964;203:417.

6. Maiman TH. Stimulated Optical Radiation in Ruby. Nature. 1960;187(4736):493-4.

7. Javan A, Bennett WR, Herriott DR. Population Inversion and Continuous Optical Maser Oscillation in a Gas Discharge Containing a He-Ne Mixture. Physical Review Letters. 1961;6(3):106-10.

8. Featherstone J, Nelson DGA. Laser Effects On Dental Hard Tissues. Adv dental res. 1987;1:21-6.

9. Weichman JA, Johnson FM. Laser use in endodontics. A preliminary investigation. Oral surgery, oral medicine, oral pathol. 1971;31(3):41620.

10. Abdo S, Mohammed A, Alhabeel M, Zetouni J. Clinical Applications of Lasers in Endodontic Review Article. J Dentistry. 2018;1:1003.

11. Cvek M. A clinical report on partial pulpotomy and capping with calcium hydroxide in permanent incisors with complicated crown fracture. J endodontics. 1978;4(8):232-7.

12. Moritz A, Schoop U, Goharkhay K, Sperr W. The $\mathrm{CO}_{2}$ laser as an aid in direct pulp capping. $\mathbf{J}$ endodontics. 1998;24(4):248-51.

13. Nair PN, Duncan HF, Pitt Ford TR, Luder HU. Histological, ultrastructural and quantitative investigations on the response of healthy human pulps to experimental capping with mineral trioxide aggregate: a randomized controlled trial. Int endodontic j. 2008;41(2):128-50.

14. Odabaş ME, Bodur H, Bariş E, Demir C. Clinical, radiographic, and histopathologic evaluation of $\mathrm{Nd}$ :YAG laser pulpotomy on human primary teeth. J endodontics. 2007;33(4):415-21.

15. Christo JE, Zilm PS, Sullivan T, Cathro PR. Efficacy of low concentrations of sodium hypochlorite and low-powered Er,Cr:YSGG laser activated irrigation against an Enterococcus faecalis biofilm. Int endodontic j. 2016;49(3):279-86.

16. Johns D, Shivashankar V, Krishnamma S, Johns M. Use of photoactivated disinfection and platelet-rich fibrin in regenerative Endodontics. $\mathrm{J}$ conservative dentistry. 2014;17:487-90.

17. Isermann GT, Kaminski EJ. Pulpal response to minimal exposure in presence of bacteria and Dycal. J endodontics. 1979;5(11):322-7.

18. Cvek M, Cleaton-Jones PE, Austin JC, Andreasen JO. Pulp reactions to exposure after experimental crown fractures or grinding in adult monkeys. J endodontics. 1982;8(9):391-7.

19. Ford TR, Torabinejad M, Abedi HR, Bakland LK, Kariyawasam SP. Using mineral trioxide aggregate as a pulp-capping material. J Am Dental Asso. 1996;127(10):1491-4.

20. OR 39 The effects of mineral trioxide aggregate on the dog pulp: Kurt Myers*, DDS, Edward Kaminski, $\mathrm{PhD}$, Eugene Lautenschlager, $\mathrm{PhD}$, Donald Miller, DDS, MS. Northwestern University Dental School, 262 E Huron, Chicago, IL 60611. J endodontics. 1996;22(4):198. 
21. Torabinejad M, Chivian N. Clinical applications of mineral trioxide aggregate. $\mathrm{J}$ endodontics. 1999;25(3):197-205.

22. Fried D, Glena RE, Featherstone JD, Seka W. Permanent and transient changes in the reflectance of $\mathrm{CO} 2$ laser-irradiated dental hard tissues at lambda $=9.3,9.6,10.3$, and 10.6 microns and at fluences of $1-20 \mathrm{~J} / \mathrm{cm}^{2}$. Lasers surg med. 1997;20(1):22-31.

23. Wigdor HA, Walsh JT, Jr. Histologic analysis of the effect on dental pulp of a 9.6-microm $\mathrm{CO}(2)$ laser. Lasers surg med. 2002;30(4):261-6.

24. White JM, Fagan MC, Goodis HE. Intrapulpal temperatures during pulsed Nd:YAG laser treatment of dentin, in vitro. J periodontol. 1994;65(3):255-9.

25. Zakariasen KL, Dederich DN, Tulip J, DeCoste S, Jensen SE, Pickard MA. Bactericidal action of carbon dioxide laser radiation in experimental dental root canals. Canadian j microbiol. 1986;32(12):9426.

26. Moshonov J, Orstavik D, Yamauchi S, Pettiette M, Trope M. Nd:YAG laser irradiation in root canal disinfection. Endodontics dental traumatol. 1995;11(5):220-24.

27. Rooney J, Midda M, Leeming J. A laboratory investigation of the bactericidal effect of a NdYAG laser. Bri dental j. 1994;176(2):61-4.

28. Fegan SE, Steiman HR. Comparative evaluation of the antibacterial effects of intracanal Nd:YAG laser irradiation: an in vitro study. $\mathrm{J}$ endodontics. 1995;21(8):415-7.

29. Gutknecht N, Moritz A, Conrads G, Sievert T, Lampert F. Bactericidal effect of the Nd:YAG laser in in vitro root canals. J clin laser med surg. 1996;14(2):77-80.

30. Le Goff A, Dautel-Morazin A, Guigand M, Vulcain $\mathrm{JM}$, Bonnaure-Mallet M. An evaluation of the $\mathrm{CO} 2$ laser for endodontic disinfection. $\mathrm{J}$ endodontics. 1999;25(2):105-8.

31. Stabholz A, Kettering J, Neev J, Torabinejad M. Effects of the $\mathrm{XeCl}$ excimer laser on Streptococcus mutans. J endodontics. 1993;19(5):232-5.

32. Folwaczny M, Liesenhoff T, Lehn N, Horch H-H. Bactericidal action of $308 \mathrm{~nm}$ excimer-laser radiation: An in vitro investigation. $\mathrm{J}$ endodontics. 1998;24(12):781-5.

33. Moritz A, Gutknecht N, Goharkhay K, Schoop U, Wernisch J, Sperr W. In vitro irradiation of infected root canals with a diode laser: results of microbiologic, infrared spectrometric, and stain penetration examinations. Quintessence international (Berlin, Germany : 1985). 1997;28(3):205-9.

34. Anić I, Tachibana H, Masumoto K, Qi P. Permeability, morphologic and temperature changes of canal dentine walls induced by $\mathrm{Nd}$ : YAG, CO2 and argon lasers. Int endodontic j. 1996;29(1):13-22.

35. Mehl A, Folwaczny M, Haffner C, Hickel R. Bactericidal effects of 2.94 microns Er:YAG-laser radiation in dental root canals. $\mathbf{J}$ endodontics. 1999;25(7):490-93.
36. Dostálová T, Jelínková H, Housová D. Endodontic treatment with application of Er:YAG laser waveguide radiation disinfection. $\mathrm{J}$ clin laser med surg. 2002;20(3):135-9.

37. Schoop U, Moritz A, Kluger W. The Er:YAG laser in endodontics: results of an in vitro study. Lasers surg med. 2002;30(5):360-4.

38. Dai T, Huang YY, Hamblin MR. Photodynamic therapy for localized infections-state of the art. Photodiagnosis photodynamic therapy. 2009;6(34):170-88.

39. De Oliveira BP, Aguiar CM, Câmara AC. Photodynamic therapy in combating the causative microorganisms from endodontic infections. Eur $\mathrm{J}$ Dent. 2014;8(3):424-30.

40. Ochsner M. Photophysical and photobiological processes in the photodynamic therapy of tumours. J photochemistry photobiol B, Biol. 1997;39(1):1-18.

41. Garcez AS, Nuñez SC, Hamblim MR, Suzuki H, Ribeiro MS. Photodynamic therapy associated with conventional endodontic treatment in patients with antibiotic-resistant microflora: a preliminary report. J endodontics. 2010;36(9):1463-6.

42. Garcez AS, Nuñez SC, Hamblin MR, Ribeiro MS. Antimicrobial effects of photodynamic therapy on patients with necrotic pulps and periapical lesion. J endodontics. 2008;34(2):138-42.

43. Garcez AS, Núñez SC, Baptista MS. Antimicrobial mechanisms behind photodynamic effect in the presence of hydrogen peroxide. Photochemical photobiol sci. 2011;10(4):483-90.

44. Williams JA, Pearson GJ, Colles MJ, Wilson M. The effect of variable energy input from a novel light source on the photoactivated bactericidal action of toluidine blue O on Streptococcus Mutans. Caries res. 2003;37(3):190-3.

45. Bago I, Plečko V, Gabrić Pandurić D, Schauperl Z, Baraba A, Anić I. Antimicrobial efficacy of a highpower diode laser, photo-activated disinfection, conventional and sonic activated irrigation during root canal treatment. Int endodontic j. 2013;46(4):339-47.

46. Rios A, He J, Glickman GN, Spears R, Schneiderman ED, Honeyman AL. Evaluation of photodynamic therapy using a light-emitting diode lamp against Enterococcus faecalis in extracted human teeth. J endodontics. 2011;37(6):856-9.

47. Payer M, Jakse N, Pertl C, Truschnegg A, Lechner E, Eskici A. The clinical effect of LLLT in endodontic surgery: a prospective study on 72 cases. Oral surg oral med oral pathol, oral radiol, endodontics. 2005;100(3):375-9.

48. Arslan H, Doğanay E, Karataş E, Ünlü MA, Ahmed HMA. Effect of Low-level Laser Therapy on Postoperative Pain after Root Canal Retreatment: A Preliminary Placebo-controlled, Triple-blind, Randomized Clinical Trial. J endodontics. 2017;43(11):1765-9.

49. Friedman S, Rotstein I, Mahamid A. In vivo efficacy of various retrofills and of $\mathrm{CO} 2$ laser in apical 
surgery. Endodontics dental traumatol. 1991;7(1):1925.

50. Bader G, Lejeune S. Prospective study of two retrograde endodontic apical preparations with and without the use of $\mathrm{CO} 2$ laser. Dental Traumatol. 1998;14(2):75-8.
Cite this article as: Abulhamayel AA, Alsulami KA, Alshehri AN, Alasmari AH, Alzahrani FR, Altayeb MA, Almane AI et al. Role of laser application in endodontic treatment: a review of literature. Int $\mathbf{J}$ Community Med Public Health 2021;8:3646-51. 